\title{
Analysis of the buckling moment on rectangular hollow pipe under pure bending load
}

\author{
Hartono Yudo ${ }^{1, *}$, Wilma Amiruddin ${ }^{1}$, Sarjito Jokosisworo ${ }^{1}$ \\ ${ }^{1}$ Naval Architecture Departement, Diponegoro University, Indonesia
}

\begin{abstract}
Not only the circle hollow pipe but also the rectangular hollow pipes are used on offshore structure. In this study, the bending moment was given at both end of pipe. The strength of buckling moment can be reduced by increasing the length. The rectangular pipe models are varying from $\mathrm{a} / \mathrm{b}$ $=1,2,4 ; \mathrm{a} / \mathrm{t}=10,15,20$ and $\mathrm{L} / \mathrm{a}=10,15,20$. On the rectangular pipe which is have larger rectangle area $(\mathrm{a} / \mathrm{b})$, have the larger deformation. Vice versa on the rectangular pipe which is have smaller rectangle area $(\mathrm{a} / \mathrm{b})$, as though on $\mathrm{a} / \mathrm{b}=2$ and $\mathrm{a} / \mathrm{b}=4$ which is have smaller deformation. The conclude that is the larger one of rectangle area then the oval deformation is large too. The buckling strength will increase with decreasing $\mathrm{a} / \mathrm{b}$ and deformation at mid span will be increase. The buckling strength decrease with increasing of $L / a$ and $\mathrm{a} / \mathrm{t}$. The strength of the buckling moment in the elastic state will decrease with increasing of $a / t$ and $a / b$. For $a / b=1$, the strength of buckling moment will tend to be equal at $\mathrm{L} / \mathrm{a}=10-20$. Pipe with increasing of $\mathrm{a} / \mathrm{t}, \mathrm{L} / \mathrm{a}$ and $\mathrm{a} / \mathrm{b}$ will be elastic.
\end{abstract}

\section{Introduction}

The damage of material when buckled is difficult to be discovered, because that is suddenly occurred. The steel is one of the important material constructions. Particularly have mechanical properties which are strong enough and the ductility. Ductility is the material ability to deform, withstand the tensile and compress before failure.

The steel have random circumstances when used. If the maximum ability of construction has been discovered, thus the construction is safe. Buckle occurred due to pressure on the steel bar which has deformation in this case through an axial compressive force. Buckle can be occurred before or after maximum stress was reached. It would not a problem if the buckle occurred after the steel passed the maximum stress. However if the buckle occurred before the steel passed maximum stress, it can be a problem because the buckle will suddenly occurred.

The structure with the rectangular hollow pipe has been used on house roof construction, the bridge pillar, port construction, the offshore construction and building construction. The typical of the neither offshore construction nor coastal construction is the casing for the pile; the offshores leg, and the funnel. The advantage of rectangular hollow pipe is the behaviour which is buckled from two directions and particularly strong enough to withstand the twisting.

* Corresponding author : hartono.yudo@yahoo.com 
In the followings, the formulas for estimating buckling stress and moment of rectangular hollow pipe subjected to bending are briefly explained.

The maximum bending stress of a rectangular pipe under the critical (buckling) moment Mcr can be expressed by Eq. 1:

$$
\sigma_{c r}=\frac{M_{c r} \mathrm{C}}{\mathrm{I}}
$$

where $\mathrm{I}$ is inertia moment and $\mathrm{C}$ is distance from neutral axis.

Timoshenko and Gere [1] expressed that the maximum compressive stress at the critical buckling moment is about $30 \%$ higher than that obtained from Eq. 1.

The previous investigation by authors (Yudo and Yoshikawa [2]) for a straight pipe the critical bending moment in linear calculation is about $10 \%$ higher than that obtained from Eq. 1.

The initial yield moment of a pipe under bending is shown below:

$$
M_{Y}=\sigma_{Y} Z
$$

Where $\sigma_{\mathrm{Y}}$ is the yield stress and $\mathrm{Z}$ is section of modulus.

Hauch and Bai [3] has earned a set of equations for calculating the maximum allowable bending moment including proposed safety factors for different targeted safety levels.

The investigation by authors (Yudo and Yoshikawa [4]) obtained the calculation results, the maximum moment for a long pipe considering oval deformation is shown as follows:

$$
M_{\max }=052 M_{c r}
$$

Yudo and Yoshikawa [5] has already investigated the imperfect pipe subjected to bending, the reduction of buckling strength due to imperfection is little bit greater in the case of large $\mathrm{D} / \mathrm{t}$ than of smaller $\mathrm{D} / \mathrm{t}$.

Essentially the rectangular hollow pipe is not only encountered the axial load. If the truss bar loaded rapidly with axial tensile force, thus the truss bar will deform. The deformation from straight circumstance of bar to be curved circumstance that told buckling.

From the mechanic of materials known that only the very short rectangular hollow pipe can be loaded until reached the yield strength, whereas the general circumstance, the spontaneous bending due to the unstability occurred before the strength of truss bar has reached that circumstance which is told buckling.

To determine the strength of rectangular pipe, the circumstance of rectangular pipe must be gave the material

Buckling can be defined as a failure phenomenon which is occurred due to compressive load with the result that causing the deformation which have the shape of lateral deflection to another equilibrium form.

Buckling phenomenon can be divided to be two sections, the global bending and local bending. An example of global bending is the entire structures have curved as one unit, whereas the local bending is the bending which is occurred at the plate elements.

To obtained critical load value, the eigenvalue should be input to this simple equation: 


$$
\mathrm{P}_{\mathrm{cr}}=\mathrm{P}_{\text {applied }} \mathrm{X} \text { Eigenvalue }
$$

Therefore, the eigenvalue which is generated also can be interpreted as the factor of safety which is having by the structure. Decreasingly of the eigenvalue which is generated, thus greater of the failure probability due to buckling. Therefore, the greater of eigenvalue expected on the analysis of structural strength to show the factor of safety.

\section{Calculation result}

The typical buckling mode, which is obtained from nonlinear calculation, is shown in Fig. 2. The stress at the lower side of the cylinder is compression, and that at the upper side is tension. The oval deformation is larger in the vicinity of midspan than at the span end. Therefore, the region of buckling is limited in the bottom area close to the center.

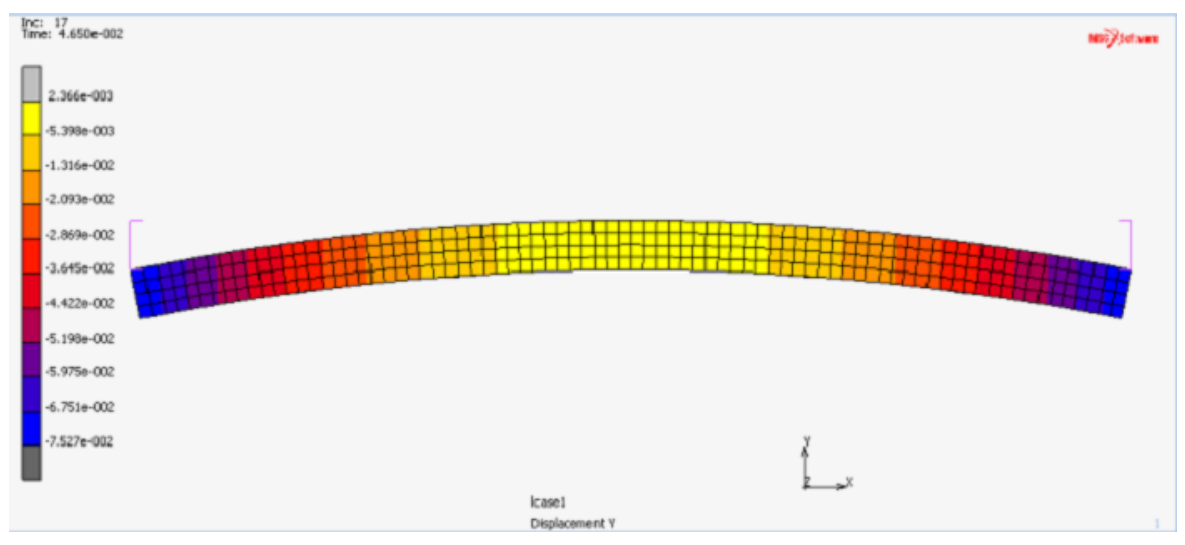

Fig.1. Rectangular pipe deformation

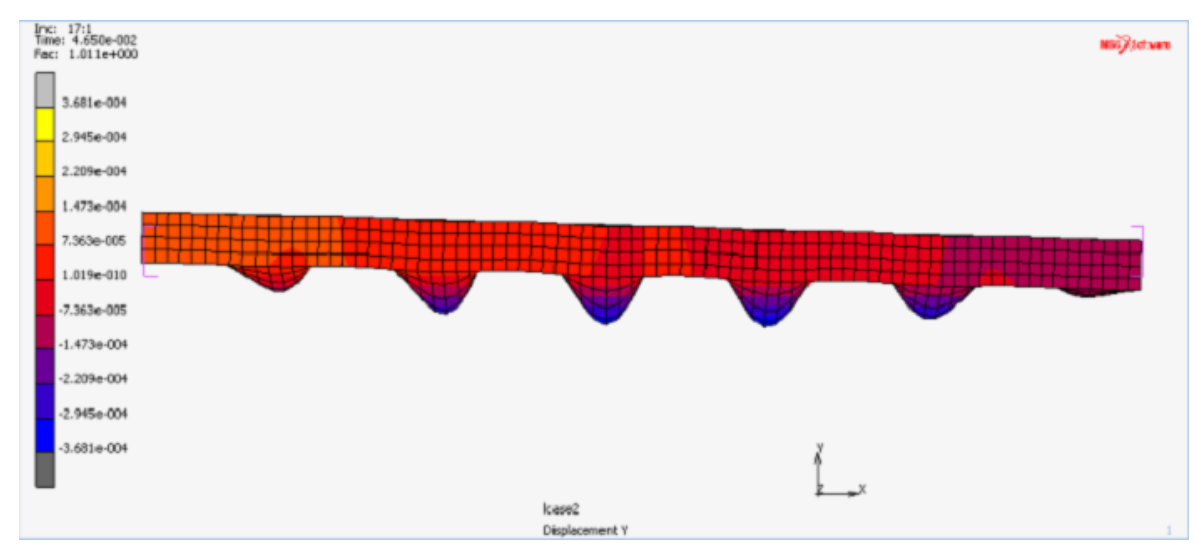

Fig.2. Rectangular pipe buckling 


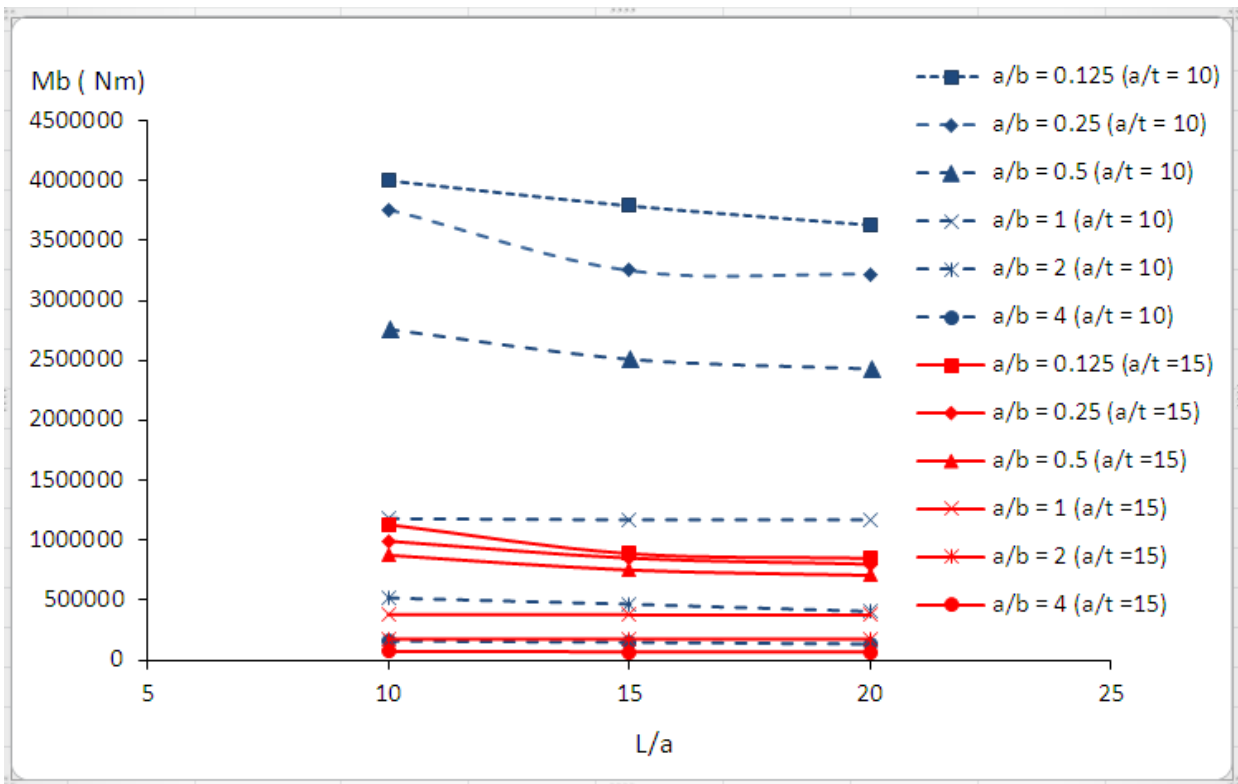

Fig.3. Relationship of buckling moment Holow pipe and L/a

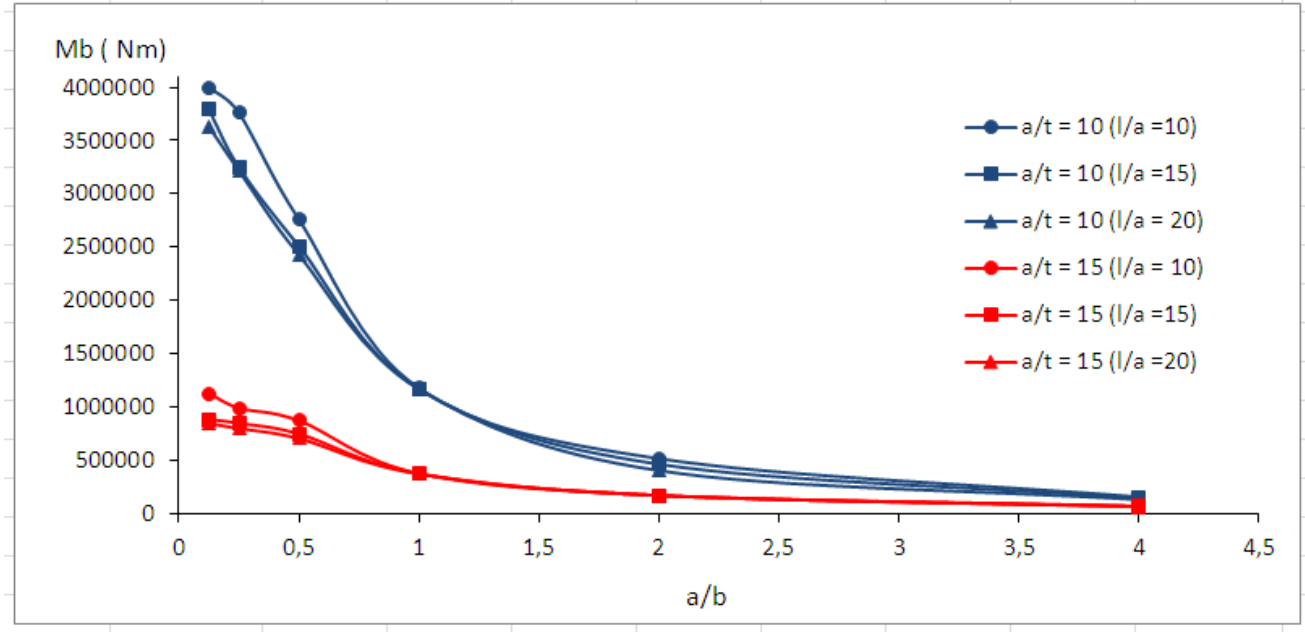

Fig.4. Relationship of buckling moments Holow pipes and $a / b$

Figure 4 shows that the strength of the buckling moment in the elastic state will decrease with increasing of $\mathrm{a} / \mathrm{t}$ and $\mathrm{a} / \mathrm{b}$. For $\mathrm{a} / \mathrm{b}=1$, the strength of buckling moment will tend to be equal at $\mathrm{L} / \mathrm{a}=10-20$. 


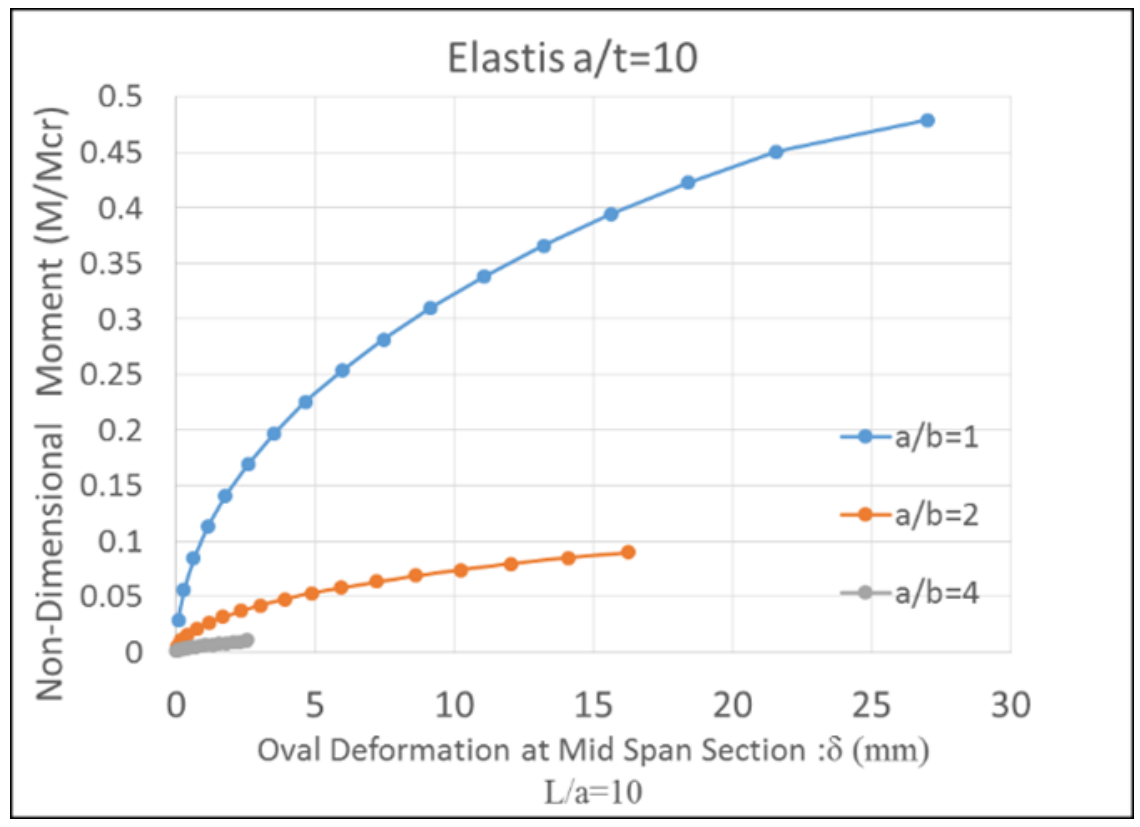

Fig.5. The deformation on middle of rectangular pipe (elastic)

On the rectangular pipe which is have larger rectangle area $(a / b)$, have the larger deformation. Vice versa on the rectangular pipe which is have smaller rectangle area $(\mathrm{a} / \mathrm{b})$, as though on $\mathrm{a} / \mathrm{b}=2$ model and $\mathrm{a} / \mathrm{b}=4$ model which is have smaller deformation. Therefore, the larger one of rectangle area the oval deformation is large too. Figure 6 shows the difference of deformation on mid-span for each rectangular pipe.

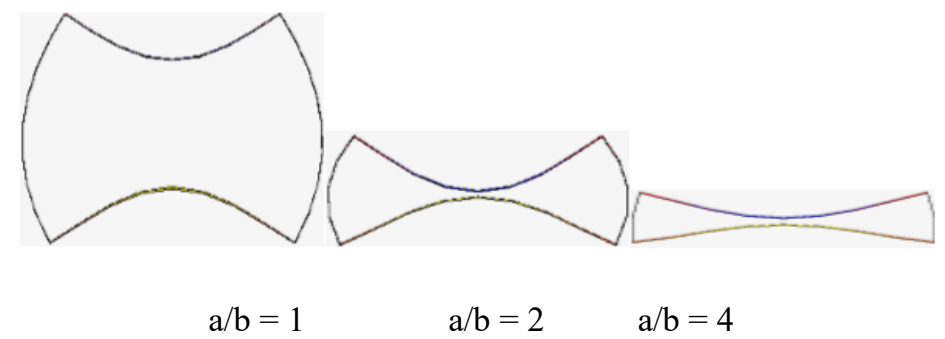

Fig.6. The deformation on mid-span of rectangular pipe (elastic)

\section{Conclusion}

In this study, the series calculations of buckling and collapse strength of rectangular hollow pipe under bending are performed by utilizing nonlinear FE software. The typical buckling modes for rectangular hollow pipes are obtained by numerical calculations. The followings are clarified by the numerical calculations.

1. The region of buckling is limited at the compressive side in the vicinity at mid span

2. The strength of the buckling moment in the elastic state will decrease with increasing of $\mathrm{a} / \mathrm{t}$ and $\mathrm{a} / \mathrm{b}$. In Figure 4 shown for $\mathrm{a} / \mathrm{b}=1$, the strength of buckling moment will tend to be equal at $\mathrm{L} / \mathrm{a}=10-20$. 


\section{Reference}

1. S. Timoshenko, J. Gere., Theory of elastic stability, 2nd edn. McGraw-Hill International Book Company, New York (1961).

2. H. Yudo, T. Yoshikawa., Mechanical behaviour of pipe under pure bending load. In: Proceedings of the 26th Asian technical exchange and advisory meeting on marine structures, pp 359-364 (2012).

3. S. Hauch, Y. Bai., Bending moment capacity of pipe. Offshore Mech Arct Eng PL99-5033 (1999).

4. H. Yudo, T. Yoshikawa., Buckling phenomenon for straight and curved pipe under pure bending. J Mar Sci Technol, vol 20, issue1, pp 94-103 (2015).

5. H. Yudo, T. Yoshikawa., Buckling phenomenon for imperfect pipe under pure bending. J Mar Sci Technol, vol 20, issue 4, pp 703-710 (2015). 